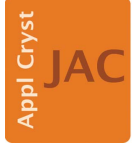

JOURNAL OF APPLIED CRYSTALLOGRAPHY

ISSN 1600-5767

\section{Managing Science: Developing your Research, Leadership and Management Skills. By Ken Peach. Oxford University Press, 2017. Pp. 288. Hardback Price GBP 25.49. ISBN 9780198796077.}

\author{
John R. Helliwell*
}

Department of Chemistry, University of Manchester, Manchester M13 9PL, UK. *Correspondence e-mail: john.helliwell@manchester.ac.uk

The title Managing Science immediately raises several questions: Who in universities, research institutes or large-equipment installations would benefit from such a text? The scientist who is going to take on some management task because they wish to get promoted? The manager who does little or no science? The scientists who have to endure an apparent complexity of management over their heads and seek illumination as to just what is going on? The sub-title Developing your Research, Leadership and Management Skills suggests it is for the heads of department alone. If so, will the book be solely retrospective? Or will it also offer prospective solutions, for example addressing the agreed ills of the science workplace the world over, such as male-dominated workplaces? I should mention that I worked alongside Ken Peach when he and I were directors of different aspects of the Council of the Central Laboratories of the Research Councils, the CCLRC. I observe that Ken Peach is very well qualified to address the topic of this book, with more than 40 years of experience managing science, in the UK and at CERN in Geneva, including 25 years at a UK university, as he puts, it managing his own science. As for the book's aim, the back cover states it is 'to introduce the working research scientist to the art and techniques of management and the skills necessary to be a good and effective manager and leader of science and scientists'. The Preface adds 'Balancing the needs of science - which has to be free to follow the trail, wherever it may lead - with the demands of society - that it be accountable, responsible and, if possible, useful - is a skill that needs to be carefully developed.' Let us see what the answers to the various questions posed above are.

After Chapter 1, an Introduction of two and a quarter pages, Chapter 2 defines and sets the boundaries of the fundamentals, namely Science, Research, Development and Scholarship. Of these four terms and their domains, scholarship is the most difficult to define but this is skilfully done. Chapter 3 continues the domains, this time in the setting of Universities and Laboratories. With a book of this sort, knowing quite where to pitch is difficult. The author opts for a down to the very basics approach and describes a university as an organization. On page 14 he states that 'The management of undergraduate teaching is beyond the remit of this book, as is some postgraduate education, namely that which leads to a taught diploma or a master's degree.' I confess to some disappointment in that decision: I consider an ideal university to be one that intertwines teaching and research such that in an undergraduate course an academic sets individual and team projects at or near to the research frontiers so as to be both not like undergraduate laboratory experiments and yet achievable in their goals. Such projects are also, besides a learning exercise, ones where both incremental and innovative research can be attempted by the first-degree student. The layout of Chapter 3 seems to me rather odd. It has section 3.1 on Universities and, later, section 3.4 on Universities as businesses. One issue that Chapter 3 might have wrestled with is the rise of managerialism in universities, adopted from the large laboratories or what might be bundled together as the 'scientific civil service', admittedly a UK terminology. Since the book is about managing science, and thereby de facto its utility, the alternative, cynical, view of management, i.e. managerialism, is outside its domain.

Chapter 4 is the first to get down to business in describing Leadership, Management and Communication. In section $4.1 \mathrm{I}$ found the opening unpromising: 'There are 
leadership opportunities and challenges at all levels - from the leader of a small section of two or three people... to the organization of several hundred scientists, engineers, technicians, administrators and support staff.' By unpromising I mean that this of course presumes a limited definition of the scientific method, since an Einstein working alone is not included. But, to be fair, managing oneself involves a different terminology, such as one's skills. The author of this book is highly experienced as a director and makes the careful, and very important, distinction about whether an organization wants a director to provide leadership or to administer it. The distinction is that an individual leading from the front, as I would call it, sounds good to the individual but could be seen as a loose cannon to the organization. This section of the book shows a depth of experience, although it avoids the psychological personality profiling formulations that might be usefully harnessed in running a team (Niemantsverdriet \& Felderhof, 2017). Section 4.2 on Management offers generic tips, including the interesting pros and cons of when a director has their door open or closed. Section 4.3 on Communication has equally helpful tips. The final section, On appointment, is aimed obviously at the new managing science recruit. This seems almost like a manual of 'how to be a politician': good words to be used on facing a first group, i.e. staff, meeting being 'evolve', 'look for new opportunities' or 'building upon', as 'these signal change without being specific or scary'. The previous section on communication offered similar 'political' guidance with its terminology: 'paltering - not exactly lying but equally not telling the truth'. In summary, 'organizations can survive a leader who cannot manage or communicate but who can delegate but they cannot survive with a leader who cannot lead'. This, however, contradicts the careful distinction made above, that leading from the front may be viewed as being a loose cannon by the organization.

Chapter 5 is Building Research Teams. This comprises sections of the book logically proceeding from graduate students to postdocs, fellows, engineers and technicians, administrators, and visitors. The latter, Visitors, is a section of considerable breadth and hints at serious problems, which fortunately occur in very few cases. Section 5.7, Team spirit, I think is very good but does need a section on, in effect, dealing with difficult people. Section 5.8, Large projects, gets into top gear, as one might expect for the author's big science background in particle physics.

Chapter 6, Recruitment, is written with a great depth of experience obviously, as becomes very clear when the author mentions near the end of the chapter that he has written hundreds of letters of reference and read thousands of them as an interviewer. The chapter is very thoroughly done. In Equal opportunities, section 6.5 , it seemed odd to me that the UK's Athena SWAN (Science Women's Academic Network) gender equality scheme, adopted now in other countries, was not mentioned, and its merit awards for equal opportunities' achievement of science departments on a hierarchical scale of bronze, silver and gold. Table 6.2 has a helpful list of forbidden questions, i.e. that cannot be asked of candidates at interview.
Chapter 7 is Managing Scientists and Others. This chapter brings us very close to the title of the whole book, clearly then a very important chapter for its aims. A manager of science is going to need to measure performance and this is where the chapter starts, with section 7.1. The chapter moves nimbly from the manager to the managed and their respective participations in the process, which should be SMART (specific, measurable, achievable, realistic and time limited). These innovations from the scientific civil service into university life have improved science in academe I think, as I explained in my own book Skills for a Scientific Life (Helliwell, 2016). Section 7.5 on dealing with problems starts with managing poor performance and deals with what is surely one of the most important aspects of any manager's role. The advice given I found clear and to the point and with sufficient detail of common types of case to be useful to the manager of science project teams. The section that is missing from this chapter is Managing your boss.

Chapter 8 is on Cooperation and Competition. After a general introduction, section 8.1 covers the topic in academia. The summing up paragraph which is highly formal may be how it works in particle physics. Rather, in my areas of science, one proceeds by deciding if you might be able to work with a person whose expertise complements your own and your laboratory's emphases, then building up from small to larger projects. Section 8.2 is on collaborations with industry and is nice and clear on the necessary formalities and full of experienced insights in several very good case studies. Section 8.3 on Multidisciplinary research is equally on the mark.

Chapter 9, Councils, Boards, Committees and Panels, is a thorough and clear treatment of the topics.

Chapter 10, Committee Meetings, again is a very thorough treatment of the topic. In my experience committees can be incredibly effective but, as the author explains well, need to be properly constituted and run. The last section, Implementing cuts in budgets, immediately raises the question of whether in fact a committee of stakeholders is the management tool to implement them.

Chapter 11, Reviewing Research, Making Proposals and Evaluating Science, shows the author in full stride with his wealth of experience of these. A thorough description of various types and situations involving peer review, and writing one's own proposals anticipating the peer review to come, is given. The examples and anecdotes keep the chapter alive, along with its naturally fairly mundane but essential details. An unexpected gap is the absence of a description of the peer review of articles submitted for publication and, increasingly, the need to scrutinize the underpinning data to improve the reproducibility and quality standards of research narratives in journals. In the large-scale facilities section, practical criteria could have been offered for judging whether a facility is operating at a world-ranked level. There are well established metrics at such facilities, whether in Europe, the Americas or Asia, for this and peer review, the subject of this chapter, extends to facilities. This is an important aspect of managing science well, and, being a big team effort for facility staff and many thousands of principal investigators, is where the 
military style works at its best, i.e. managerial methodology is essential here. The section on Preparing for an institutional review is a gem of clarity and the questions posed for selfevaluation by the institute in preparation for a review could be equally well applied to an individual academic scientist and their laboratory aims, however small or large their laboratory is. Section 11.5 is a long section. Its bulk is a masterly description, and dissection, of the UK's efforts with its Research Assessment Exercise, and its descendants. Similar exercises have been undertaken in other countries. The most serious flaw of such RAEs is how then to reach objectivity. This is addressed by the author of this book but he follows the dictum that judgement is solely what is needed. Several times he wholesale rejects the objective evidence of the various research assessment metrics on offer, which I would say can and should be moulded into the judging process.

Chapter 12, Managing Projects, is a thorough description and will be very useful to the reader persevering to the end. But some project failures would have both been instructive and added some spice. Famous ones that come to mind are the closure of the Supercollider's construction in Texas and the mis-polished mirrors of the Hubble Space Telescope. For balance, some praiseworthy ones would be good, e.g. the wiggler 5T cryomagnet for the Synchrotron Radiation Source (SRS) at Daresbury, which was built by the Rutherford Appleton Laboratory; this was a ground-breaking device in synchrotron radiation production, with pioneering applications in various scientific fields.

Chapter 13 on Risk is a vital topic in planning and managing science everywhere, as I have seen serving on numerous international advisory committees. Again the author gives a masterly description in the sections on Evaluating and managing risk, on The risk register, and on Risk, reward, investment and progress. Tables 13.1 and 13.2 are very helpful, as are Figures 13.1 and 13.2. Section 13.3 on Reputation risk, although lucid, important and clear, does not sit well in this chapter and would fit better I think in a dedicated ethics chapter.

Chapter 14 is on Health and Safety, a key part of managing science. This description is generally good. Some mention could have been made of chemical hazards and their safe-aspossible use, the 'fail safe design' of equipment, radiation protection, and safe use of lasers, to mention a few of the more common areas of scientific research requiring 'safety rules'. But obviously a dedicated description of each would not really be feasible in a book of this type.

Chapter 15 is on Dealing with Disaster. A nice explanation is given with the practical example of magnets failure at CERN in 2008, which delayed the Large Hadron Collider (LHC) project for a year. I recalled various aspects of this from memory of the media coverage at the time, and so the chapter's principles and practice related well to business continuity planning of the LHC research programme example. Also, the examples of data recovery planning were well chosen. Even as individuals, we also know the virtues of regular disk backups, and I would emphasize that as advice to my students. The final section on insurance I did not parti- cularly like and disagreed with the life insurance analysis analogy offered; if you are a major wage earner for the family, you have to provide for your dependants; it is not a 'saving money in a jar' type of thing.

Chapter 16 is on Problems. Page 226 provides a pretty comprehensive list of what is to be covered in the chapter and indeed what a manager might face. Very good generic examples follow of poor performance examples: due to alcohol abuse or misuse of computers of various kinds, and a remuneration grievance example. The category of bullying is not dealt with in detail although it is commonplace, not least in institutions under the great pressure of research and teaching performance assessment, where managers can seem to 'simply' transfer these pressures to their staff. The obvious conflict of interest here for the manager is a major complication in fair handling of staff complaints against department heads. So, the role of the trade union can be vitally supportive in ways that the employer and their managers in effect are not. Staff exiting from their employment can be confidentially canvassed to track such problems at an employer; indeed, this is a tool used to check for diversity discrimination, such as a department with a bullying culture. This is identified as being a significant contributor to male-female gender disparities in staffing. The chapter concludes with details of preparing for difficult interviews. The author is to be commended on being candid and sharing his approach; the context I felt was not good, however, and presumably represents the approach of a particular employer and their managerial training sessions. An emphasis on having prepared negotiating positions and 'sides' clearly suggests a wish for an outcome on behalf of the organization. An unsatisfied employment staff grievance can escalate into legal actions such as an employment tribunal process. This is then a big topic only lightly touched on, with variations of legal process in different countries.

Chapter 17 is somewhat mysteriously entitled Just Managing, but the author neatly, and you will just have to buy the book to find out, explains its threefold pun. Section 17.1 is on Ethical management. Here we touch the nerve exposed already in the previous chapter. Interestingly the principles quoted are from the UK Engineering Council and are good, as far as they go. But science and engineering are not one and the same; what does not appear in the list is authorship or data or peer review in science. These are, however, dealt with in other parts of the book, which is a fair defence of it. Section 17.2 is The stressed manager. The text here is from a highly experienced manager and I would largely concur with it, but the 'schedule meetings starting at 4 p.m.' advice could be seen as one of the causes of the male-dominated workplace, especially in the higher positions of an organization. The time management tips although insightful miss the very useful one I learnt on a course, namely the time management quadrant and how one should personally strive to be in the important not urgent quadrant. Also, any situation forcing you into the important and urgent quadrant, i.e. firefighting, should be treated in two steps: put the fire out and then make sure it does not happen again! Section 17.3 is Management is management. It contains sage advice on accounting, auditing, 
grant management, and laboratory and office space management.

Chapter 18, Summary and Conclusions, is just that, but also offers a valedictory speech. It makes clear that 'Although I enjoyed my years in the various senior management positions, I cannot say I enjoyed them more than I enjoyed doing science.'

So, can one 'herd cats', where the 'cats' I define here are creative, free thinking, imaginative scientists? This book convinces me that they can be, at least when united by the vision to achieve a grand science challenge or have a multiscience large-equipment user facility. It is indeed the classic image of particle physics united to find, say, the Higgs boson. However, could an old-days Einstein or a modern-days Higgs have been 'managed'? Does one even need a person in control who is a scientist, or does having a non-scientist in charge result in objective leadership?
Overall this book is an excellent manual and assistant to the professional scientist. It is carefully prepared by a highly experienced senior scientist. There are some caveats, which I have indicated specifically in this book review; these could be readily addressed in a second edition.

\section{Acknowledgements}

I am grateful to the Book Reviews Editor Massimo Nespolo for his comments on this book review which improved it, notably capturing better the international aspects.

\section{References}

Helliwell, J. R. (2016). Skills for a Scientific Life. Boca Raton: CRC Press, Taylor and Francis Group.

Niemantsverdriet, J. W. \& Felderhof, J-K. (2017). Scientific Leadership. Berlin, Boston: De Gruyter. 